\title{
Prostate Stromal Sarcoma
}

National Cancer Institute

\section{Source}

National Cancer Institute. Prostate Stromal Sarcoma. NCI Thesaurus. Code C5524.

A rare malignant neoplasm arising from specialized prostatic stroma. It is characterized by the presence of stromal overg rowth and hypercellularity, increased number of mitotic figures, and pleomorphism. 